\title{
Modeling Pressure Characteristics of Centrifugal Compressor Step
}

\author{
Vladimir A. Kulagin ${ }^{\mathrm{a} *}$ and Alexander G. Nikiforov ${ }^{\mathrm{b}}$ \\ ${ }^{a}$ Siberian Federal University \\ 79 Svobodny, Krasnoyarsk, 660041, Russia \\ ${ }^{b}$ Smolensk State Agricultural Academy \\ 10/2 Great Soviet Str., Smolensk, 214000, Russia
}

Received 04.02.2017, received in revised form 11.03.2017, accepted 29.04.2017

Proposed is the method to calculate work coefficient versus flow rate coefficient with accuracy inside test accuracy. The method is based on neural simulation and is trained (identified) on 101 tests of model stages with wide range of flow rate coefficients, work coefficients and impeller Mach numbers.

Keywords: head performance, work coefficient, flow rate coefficient, neural model, physical model.

Citation: Kulagin V.A., Nikiforov A.G. Modeling pressure characteristics of centrifugal compressor step, J. Sib. Fed. Univ. Eng. technol., 2017, 10(3), 388-398. DOI: 10.17516/1999-494X-2017-10-3-388-398.

\section{Моделирование напорной характеристики центробежной компрессорной ступени}

\author{
В.А. Кулагин ${ }^{a}$, А.Г. Никифоров ${ }^{\sigma}$ \\ ${ }^{a}$ Сибирский федеральный университет \\ Россия, 660041, Красноярск, пр. Свободный, 79 \\ ${ }^{6}$ Смоленская ГСХА \\ Россия, 214000, Смоленск, ул. Большая Советская, 10/2
}

Методом нейронного моделирования получен способ расчета зависимости коэффициента внутреннего напора от коэффициента расхода центробежных компрессорных ступеней с отклонением в пределах точности экспериментов. Для обучения (идентификации) модели использована 101 измеренная характеристика модельных ступеней трех производителей в очень широком диапазоне коэффищиентов расхода, коэффициентов напора и условных чисел Maxa.

Ключевые слова: напорная характеристика, коэффициент внутреннего напора, коэффициент расхода, нейронная модель, физическая модель.

(C) Siberian Federal University. All rights reserved

* Corresponding author E-mail address: v.a.kulagin@mail.ru 
Несмотря на быстрое развитие методов вычислительной газодинамики, инженерные методики проектирования и расчета центробежных компрессоров не теряют актуальности, а все более востребованы. Их совершенствованию уделяют внимание и отечественные, и зарубежные специалисты [17]. Важно иметь надежный математический аппарат для расчета газодинамических характеристик ступени с любой практически применимой проточной частью.

Формально задача не является сложной. Достаточна возможность рассчитать КПД и коэффициент внутреннего напора в зависимости от условного коэффициента расхода, которым пользуется Политехническая школа [4] и ряд зарубежных специалистов, или одним из физических коэффициентов расхода, который предпочитают другие. Однако практически решение представляется достаточно сложным. Например, авторы новых версий Метода универсального моделирования для расчета коэффициентов потерь используют более двух десятков алгебраических уравнений с 65 эмпирическими коэффициентами $[8,9]$. Система алгебраических уравнений базируется на физической схеме течения, т.е. на нескольких экспериментально подтвержденных или построенных логически допущениях. Причинами потерь напора считается трение газа о поверхности проточной части и вихревые потери, возникающие при отрыве пограничного слоя на участках замедленного течения. На основе результатов визуализации принято, что вихревые потери в рабочем колесе могут появляться только на стороне разрежения рабочих лопаток, и т.д. Математические модели такого рода носят, по существу, произвольный характер, отражающий взгляды разработчика в тот или иной момент.

Следует отдать должное создателям упомянутых инженерных методов [17], преодолевших значительные трудности и с успехом применяющих компьютерные программы на базе математических моделей в проектной практике. Авторы настоящего текста полагают, что развитие прикладной математики и вычислительной техники сделало актуальным применение альтернативного способа расчета характеристик центробежных компрессорных ступеней. Программные пакеты для построения нейросетей дают возможность создания математических моделей, не прибегая к построению физических моделей и их математическому описанию. Попытки такого рода представлены в публикациях [10-12]. Характеристики КПД и коэффициента политропного напора большого количества разнообразных ступеней моделируются с точностью, соизмеримой с точностью экспериментального определения характеристик. Достаточно успешны и результаты моделирования параметра эффективности безлопаточных диффузоров. Нейронными сетями смоделированы характеристики коэффициента трения серии безлопаточных диффузоров, определенные CFD-расчетами.

Можно полагать, что «нейронные» модели пригодны для решения прямой задачи газодинамики - расчет газодинамических характеристик центробежной ступени с заданными размерами при заданных начальных условиях. «Физические» математические модели решают и обратную задачу - позволяют найти оптимальную форму проточной части, при которой заданные расход и конечное давление будут получены при максимальном КПД. За счет быстродействия программы Метода универсального моделирования [4] выполняют эту работу перебором вариантов. Опыта успешного применения «нейронных» моделей для решения подобной задачи пока нет. Будущие исследования дадут ответ на этот вопрос. Настоящий текст посвящен более простой задаче - моделированию напорной характеристики центробежной компрессорной ступени.

$$
-389-
$$


В безразмерном виде по результатам испытания характеристики ступени удобно представлять как:

$$
\eta^{*}, \psi_{\mathrm{i}}=\mathrm{f}(\Phi) .
$$

В соответствии с известными соотношениями между безразмерными и размерными параметрами:

- массовый расход

$$
\overline{\mathrm{m}}=\frac{\mathrm{p}_{0}^{*}}{\mathrm{RT}_{0}^{*}} \Phi \frac{3,141}{4} \mathrm{D}_{2}^{2} \mathrm{u}_{2}
$$

- отношение давлений

$$
\frac{\mathrm{p}_{0^{\prime}}^{*}}{\mathrm{p}_{0}^{*}}=\left(1+(\mathrm{k}-1) \psi_{\mathrm{i}} \mathrm{M}_{\mathrm{u}}^{2}\right)
$$

где $\mathrm{M}_{\mathrm{u}}=\frac{\mathrm{u}_{2}}{\sqrt{\mathrm{kRT}_{0}^{*}}}$

- мощность привода ступени

$$
\mathrm{N}_{\mathrm{i}}=\overline{\mathrm{m}} \psi_{\mathrm{i}} \mathrm{u}_{2}^{2}=\Phi \psi_{\mathrm{i}} \frac{\mathrm{p}_{0}^{*}}{\mathrm{RT}_{0}^{*}} \frac{3,141}{4} \mathrm{D}_{2}^{2} \mathrm{u}_{2}^{3} .
$$

Авторы разработали нейронную модель характеристики внутреннего напора $\psi_{\mathrm{i}}=\mathrm{f}(\Phi)$. Для идентификации (применительно к нейтронным сетям процесс называют обучением) использованы характеристики внутреннего напора центробежных компрессорных ступеней промежуточного типа РК+БЛД+ОНА. Обработаны результаты испытаний трех групп модельных ступеней:

- компании «Dresser\&Clark» (США), лицензия на которые была приобретена в 1970-е гг.;

- проблемной лаборатории компрессоростроения ЛПИ [13, 14];

- Невского машиностроительного завода.

Проточная часть ступеней состоит из рабочего колеса с радиально расположенными лопатками цилиндрической формы, безлопаточного диффузора. На рис. 1 показана схема, общая для всех 39 ступеней, участвовавших в идентификации.

Соотношения размеров количество лопаток и лопаточные углы ступеней лежат в широком диапазоне. Границы изменения конструктивных параметров ступеней, выбранных для идентификации моделей, указаны в табл. 1.

Величина коэффициента напора определяется соотношениями размеров рабочего колеca, формой и количеством лопаток. В монографии [14] приведены экспериментальные данные, которые указывают на влияние формы диффузора на коэффициент напора. Имеет место влияние последующего элемента проточной части на работу предшествующего. Поэтому в таблице приведены геометрические соотношения всех элементов проточной части. В процессе идентификации соотношения размеров ОНА получили низкие весовые коэффициенты, поскольку этот элемент значительно удален от рабочего колеса и не оказывает на него влияния. 


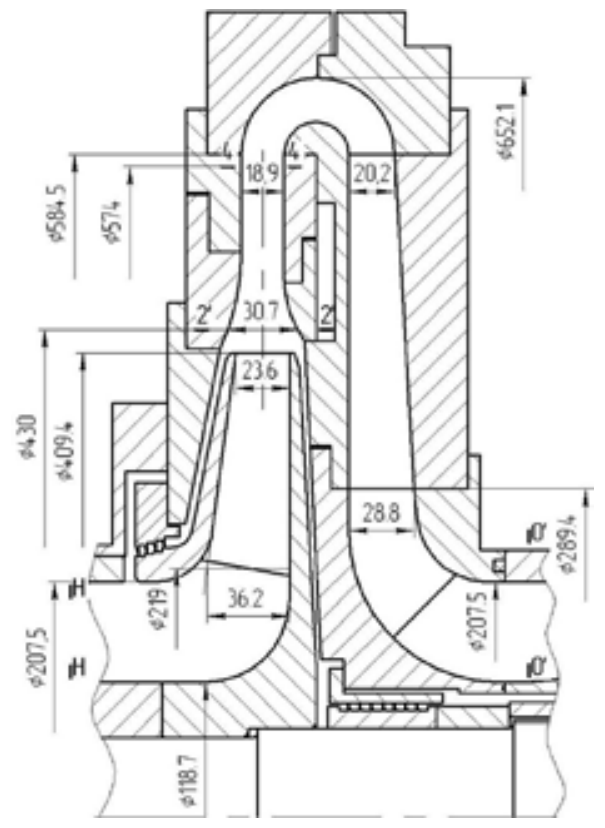

Рис. 1. Схема модельной ступени проблемной лаборатории компрессоростроения ЛПИ

Экспериментальные исследования ступеней при различных условных числах Маха в диапазоне $\mathrm{M}_{\mathrm{u}}=0,327-0,920$ позволили получить данные по 101 газодинамической характеристике КПД и напора. В каждой из них внутренний напор измерялся в 46 точках по расходу. Таким образом, выборка исходных данных для идентификации модели составила 567 наборов значений.

Представленный выше набор ступеней, помимо широкого диапазона геометрических размеров, имеет достаточно плотную детализацию промежуточных значений. Внутри диапазонов геометрических параметров (табл. 1) содержится большое количество их значений, например:

- ряд чисел лопаток: $13 ; 15 ; 17 ; 18 ; 19 ; 20 ; 21$;

- ряд выходных углов лопаток РК $\beta_{л 2}=22,5^{\circ} ; 27,8^{\circ} ; 35,01^{\circ} ; 37^{\circ} ; 40,5^{\circ} ; 8,49^{\circ} ; 52,1^{\circ} ; 56,9^{\circ}$; $85,5^{\circ}$

- ряд входных углов лопаток $\beta_{л 1}=24,39^{\circ} ; 28,6^{\circ} ; 29,4^{\circ} ; 33,45^{\circ} ; 34,4^{\circ} ; 37,39^{\circ} ; 37,41^{\circ} ; 37,47^{\circ}$; $37,61^{\circ}$;

- ряд условных чисел Маха $\mathrm{M}_{u}=0,327 ; 0,36 ; 0,589 ; 0,6 ; 0,601 ; 0,603 ; 0,604 ; 0,605 ; 0,648 ; 0,66$; 0,$785 ; 0,79 ; 0,791 ; 0,792 ; 0,793 ; 0,794 ; 0,795 ; 0,796 ; 0,798 ; 0,864 ; 0,917 ; 0,919 ; 0,92$.

Условный коэффициент расхода Ф охватывает диапазон значений от 0,0024 до 0,126 , распределенных достаточно равномерно. На область от 0,0024 до 0,05 приходится 421 из 567 точек характеристик.

Представленные в исходной выборке данные описывают ступени с политропным КПД $\eta$ от 0,33 до 0,848 и коэффициентом политропного напора $\psi_{i}$ в диапазоне от 0,051 до 0,618 .

В ходе работы была поставлена задача создать модель, рассчитывающую внутренний напор $\psi_{i}$ в виде зависимостей $f\left(\Phi, M_{u}, G\right)$ от условного коэффициента расхода, условного числа Маха и совокупности параметров, описывающих геометрию проточной части (обозначены как $G)$. 
Таблица 1. Диапазон значений геометрических параметров ступеней

\begin{tabular}{|c|c|c|c|}
\hline Название параметра & Обозначение & Минимум & Максимум \\
\hline Относительный диаметр втулки & $\mathrm{D}_{\mathrm{BT}} / \mathrm{D}_{2}$ & 0,25 & 0,3916 \\
\hline Относительный диаметр уплотнения & $\mathrm{D}_{\mathrm{y} \Pi} / \mathrm{D}_{2}$ & 0,436 & 0,592 \\
\hline Число лопаток РК & $\mathrm{Z}_{\mathrm{PK}}$ & 13 & 21 \\
\hline Относительная толщина лопатки РК & $\delta_{\mathrm{PK}} / \mathrm{D}_{2}$ & 0,007 & 0,017 \\
\hline Относительный диаметр в сечении ступени 0-0 & $\mathrm{D}_{0} / \mathrm{D}_{2}$ & 0,425 & 0,573 \\
\hline Относительный диаметр на входе в РК & $\mathrm{D}_{1} / \mathrm{D}_{2}$ & 0,502 & 0,668 \\
\hline Относительная высота лопатки на входе в РК & $\mathrm{b}_{1} / \mathrm{D}_{2}$ & 0,0063 & 0,124 \\
\hline Относительная высота лопатки на выходе из РК & $\mathrm{b}_{2} / \mathrm{D}_{2}$ & 0,0063 & 0,069 \\
\hline Угол установки лопатки $\beta_{\text {л1 }}$ на входе в РК & $\beta_{\mathrm{L} 1}$ & $24,39^{\circ}$ & $37,61^{\circ}$ \\
\hline Угол установки лопатки $\beta_{\text {л2 }}$ на выходе из РК & $\beta_{\text {Л } 2}$ & $22,5^{\circ}$ & $85,5^{\circ}$ \\
\hline Относительный радиус закругления основного диска РК & $\mathrm{R}_{\mathrm{S} 1} / \mathrm{D}_{2}$ & 0 & 0,128 \\
\hline Относительный радиус закругления покрывного диска РК & $\mathrm{R}_{\mathrm{S} 2} / \mathrm{D}_{2}$ & 0 & 0,0653 \\
\hline Относительный диаметр на входе в БЛД & $\mathrm{D}_{3} / \mathrm{D}_{2}$ & 1,01 & 1,05 \\
\hline Относительный диаметр на выходе из БЛД & $\mathrm{D}_{4} / \mathrm{D}_{2}$ & 1,41 & 1,56 \\
\hline Относительная ширина проточной части на входе в БЛД & $\mathrm{b}_{3} / \mathrm{D}_{2}$ & 0,0056 & 0,069 \\
\hline Относительная ширина проточной части на выходе из БЛД & $\mathrm{b}_{4} / \mathrm{D}_{2}$ & 0,0056 & 0,069 \\
\hline Относительный диаметр входа в лопаточную решетку ОНА & $\mathrm{D}_{5} / \mathrm{D}_{2}$ & 1,41 & 1,56 \\
\hline $\begin{array}{l}\text { Относительный диаметр выхода из лопаточной решетки } \\
\text { ОНА }\end{array}$ & $\mathrm{D}_{6} / \mathrm{D}_{2}$ & 0,577 & 0,818 \\
\hline Относительная ширина проточной части на входе ОНА & $\mathrm{b}_{5} / \mathrm{D}_{2}$ & 0,033 & 0,085 \\
\hline Относительная ширина проточной части на выходе ОНА & $\mathrm{b}_{6} / \mathrm{D}_{2}$ & 0,033 & 0,085 \\
\hline $\begin{array}{l}\text { Относительный диаметр проточной части на выходе из } \\
\text { ступени }\end{array}$ & $\mathrm{D}_{0} / \mathrm{D}_{2}$ & 0,475 & 0,625 \\
\hline Относительный внешний радиус поворотного колена & $\mathrm{R}_{3} / \mathrm{D}_{2}$ & 0,0716 & 0,159 \\
\hline Относительный внутренний радиус поворотного колена & $\mathrm{R}_{4} / \mathrm{D}_{2}$ & 0,032 & 0,0739 \\
\hline Угол установки лопатки $\alpha_{\text {л5 }}$ (в градусах) на входе в ОНА & $\alpha_{\text {Л5 }}$ & 8,6 & 37 \\
\hline Число лопаток ОНА & $\mathrm{z}_{\mathrm{OHA}}$ & 16 & 32 \\
\hline Относительная толщина лопаток ОНА & $\delta_{\mathrm{OHA}} / \mathrm{D}_{2}$ & 0,028 & 0,057 \\
\hline
\end{tabular}

На подготовительном этапе было создано несколько видов моделей с разной структурой нейронной сети и параметрами обучения. Из них были выбрана сеть с наименьшей средней квадратичной ошибкой.

Для моделирования значений внутреннего напора использовалась сеть, состоящая из двух слоев, 20 нейронов в первом слое и 1 нейрона - во втором. Функции активации слоев нейронов в моделях: logsig (логическая сигмоида) для первого слоя и pureline (линейная) для второго слоя.

При анализе результатов выяснилась специфическая особенность экспериментальных характеристик лицензионных и отечественных ступеней. Типичный пример характеристик $\eta^{*}, \psi_{\mathrm{i}}=\mathrm{f}(\Phi)$ отечественной модельной ступени показан на рис. 2.

Графики демонстрируют минимальный разброс точек относительно линейной зависимости $\eta^{*}, \psi_{\mathrm{i}}=\mathrm{f}(\Phi)$. 


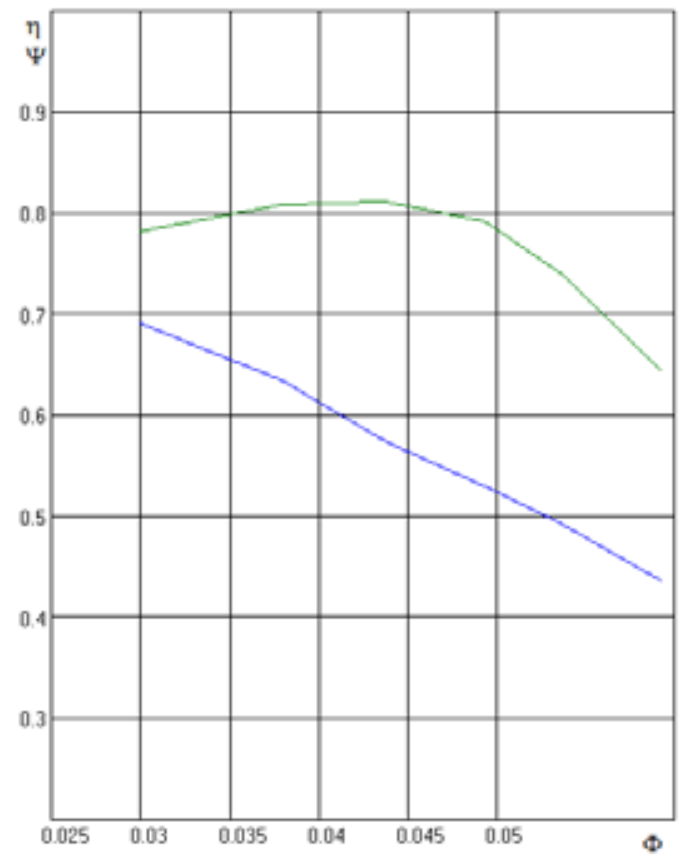

Рис. 2. Пример характеристикимодельной ступени в координатах $\eta^{*}, \psi_{\mathrm{i}}=\mathrm{f}(\Phi)$

Характеристики лицензионных ступеней представлены в виде зависимостей $\eta^{*}, \psi_{\mathrm{i}}=\mathrm{f}(\Phi)$. Коэффициент политропного напора связан с коэффициентом внутреннего напора через КПД:

$$
\psi_{\mathrm{i}}=\frac{\psi_{\mathrm{p}}}{\eta^{*}}
$$

Для лицензионных ступеней внутренний напор получен из исходных данных отношением коэффициента напора к политропному КПД по соотношению (5). На значительный разброс точек на графиках КПД и коэффициента политропного напора некоторых сверхмалорасходных ступеней не обращали внимания, так как в целом зависимости не противоречили известным закономерностям. Но у этой части ступеней получился незакономерный и значительный разброс относительно линейной зависимости. Характерные примеры представлены на рис. 3.

На рис. 3 приведены характеристики двух близких по параметрам сверхмалорасходных ступеней с различным отклонением от линейной зависимости $\eta^{*}, \psi_{\mathrm{i}}=\mathrm{f}(\Phi)$. Трудности корректного измерения параметров потока при испытаниях сверхмалорасходных ступеней очевидны, но не исключают возможности корректных измерений. На рис. 4 показаны характеристики сверхмалорасходной ступени и среднерасходной ступени с корректно измеренной характеристикой $\eta^{*}, \psi_{\mathrm{i}}=\mathrm{f}(\Phi)$.

Средняя ошибка по всем 567 входным векторам обучающей выборки расчётных значений внутреннего напора $\psi_{i}=\mathrm{f}\left(G, \Phi, M_{u}\right)$ составила $1,83 \%$. Если не учитывать крайние по расходу точки, то среднее отклонение расчётных значений внутреннего напора на оптимальных режимах не превышает 1,5 \%. Без ступеней с некорректно измеренными коэффициентами напора 

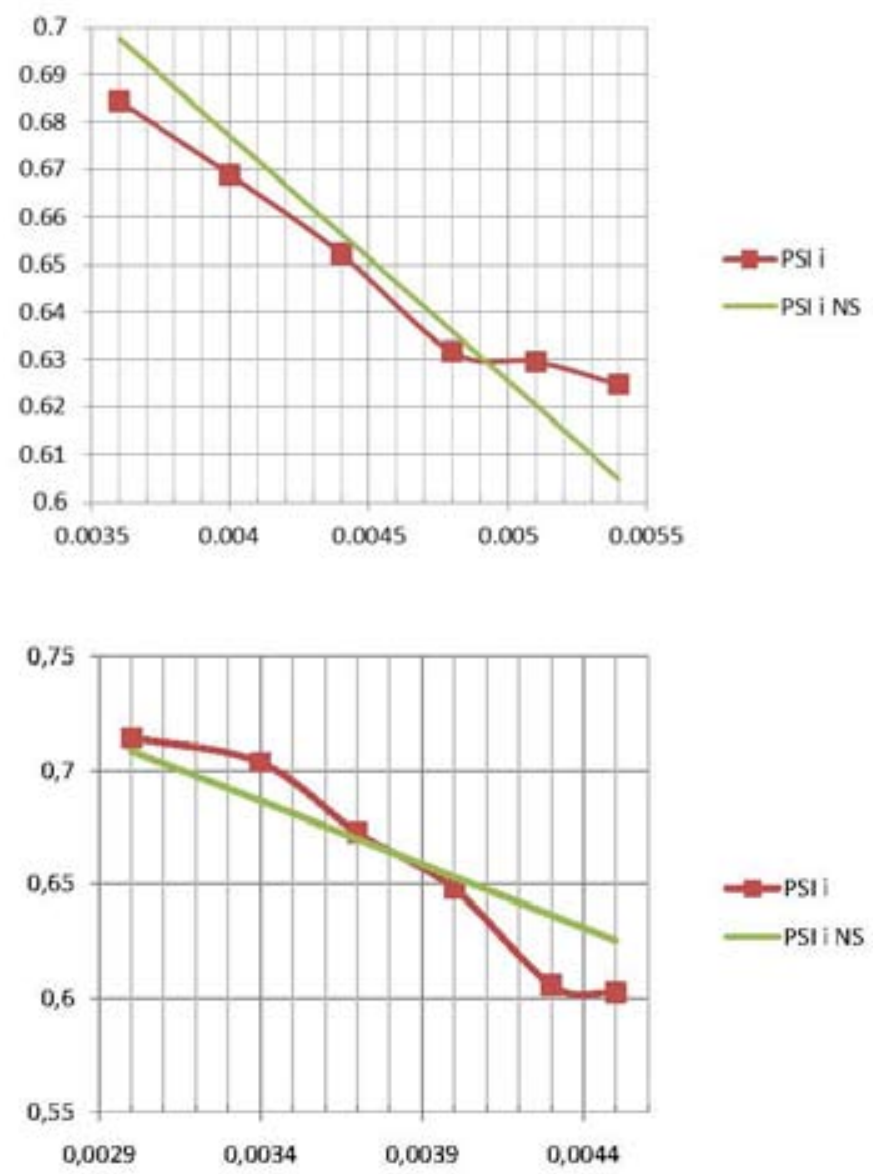

Рис. 3. Примеры измеренных с большой погрешностью характеристик $\eta^{*}, \psi_{\mathrm{i}}=\mathrm{f}(\Phi)$ лицензионных ступеней фирмы Dresser-Clark и результат моделирования

отклонение уменьшается до 0,7 \%, что соизмеримо с погрешностью тщательно проведенных экспериментов.

Авторы обращают внимание разработчиков инженерных проектировочных программ на полученный результат. В работе [14] представлены результаты моделирования напорной характеристики коэффициента теоретического напора на основе «физической» модели. Сопоставление показывает следующее:

- нейронное моделирование обеспечило более высокую точность для гораздо большей количественно выборки ступеней и с гораздо большим диапазоном коэффициентов напора и расхода;

- технически получить результат при нейронном моделировании проще. Авторам работы [15] пришлось не только использовать результаты экспериментов с модельными ступенями, но также воспользоваться ранее проведенными численными экспериментами расчетами напорных характеристик рабочих колес при невязком обтекании $[16,17]$.

Вместе с тем следует отметить определенную опасность некритичного использования математических методов без анализа физической сущности получаемых результатов. На рис. 5 

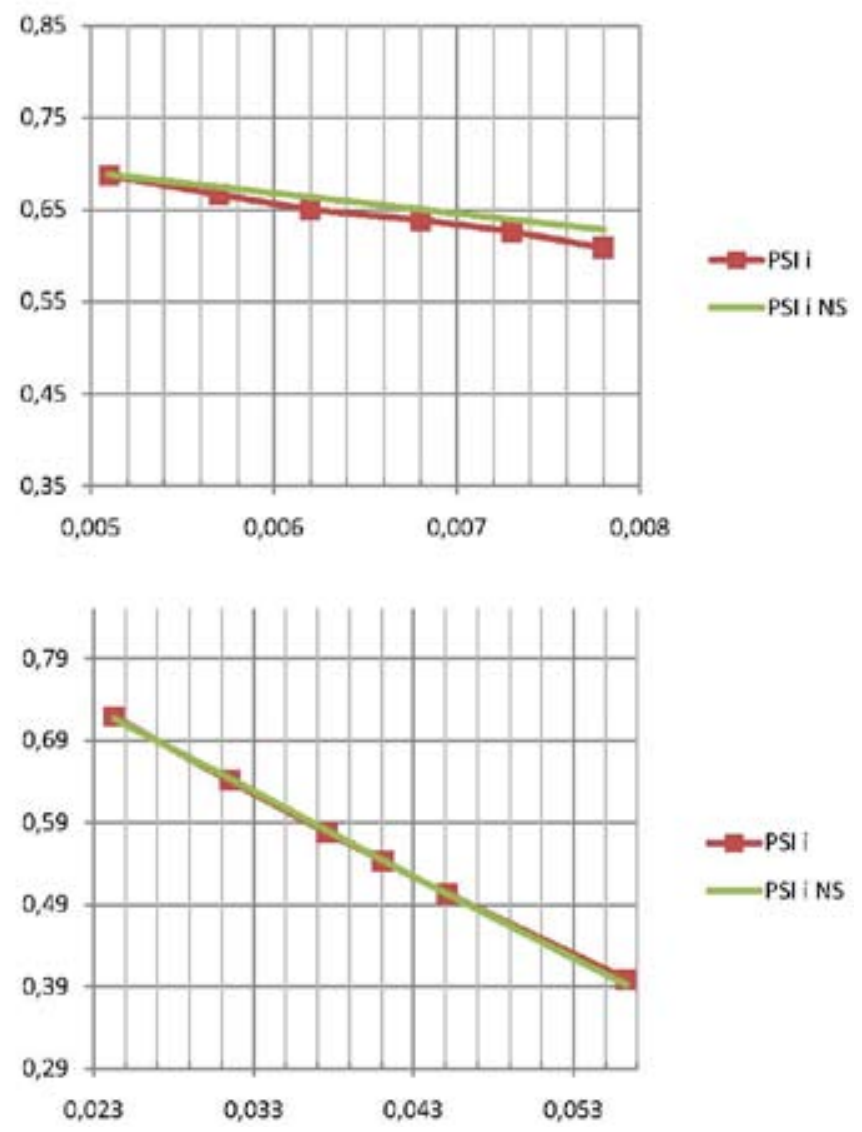

Рис. 4. Примеры корректно измеренных характеристик $\eta^{*}, \psi_{\mathrm{i}}=\mathrm{f}(\Phi)$ и результат моделирования

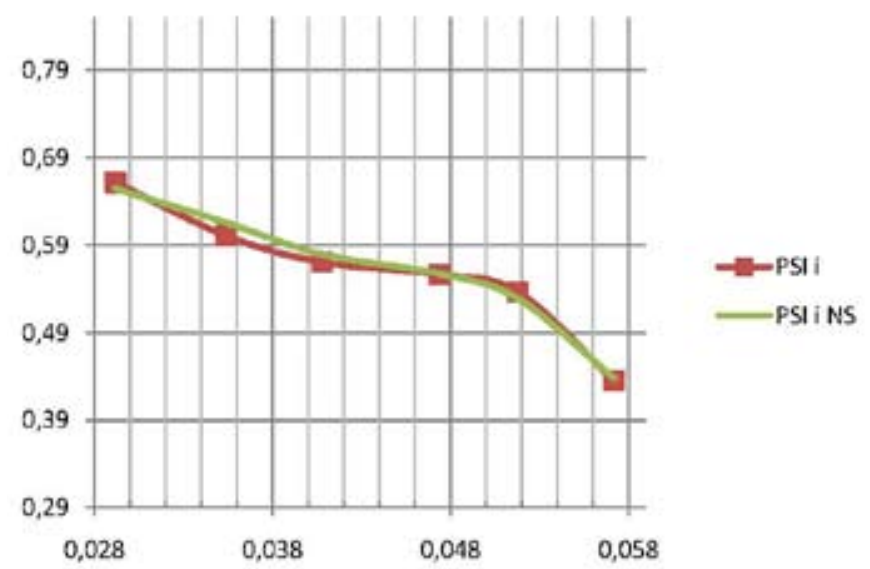

Рис. 5. Пример некорректно измеренной характеристики $\eta^{*}, \psi_{\mathrm{i}}=\mathrm{f}(\Phi)$ среднерасходной ступени и результат моделирования 
приведена некорректно измеренная характеристика $\eta^{*}, \psi_{\mathrm{i}}=\mathrm{f}(\Phi)$ среднерасходной ступени и результат моделирования.

Несмотря на явную ошибку измерений, нейронная модель точно повторила результаты ошибочного эксперимента. В данном случае ошибка измерений и моделирования очевидна, и виден путь предотвращения подобной ошибки. При моделировании характеристики КПД подобное труднее выявить и устранить. Нейронное моделирование газодинамических характеристик центробежных ступеней следует продолжить и тщательно проанализировать.

Исследование выполнено при финансовой поддержке Российского фонда фундаментальных исследований, Правительства Красноярского края, Красноярского краевого фонда поддержки научной и научно-технической деятельности в рамках научного проекта № 16-41-242156p_oфu_м

\section{Список литературы}

[1] Лунев А.Т., Вячкилев О.А., Дроздов Ю.В. Проектирование центробежных компрессорных ступеней на основе математической модели. Проектирование и исследование компрессорных машин. Казань, 1997, 3 [Lunev A.T., Vyachkilev O.A., Drozdov Yu.V. Designing of centrifugal compressor stages on the basis of of a mathematical model. Design and research of compressor machines. Kazan, 1997, 3 (in Russian)]

[2] Лунев А.Т. Разработка высокоэффективных сменных проточных частей центробежных компрессоров газоперекачивающих агрегатов. Дис ... канд. техн. наук. Казань. 2005 [Lunev A.T. Development of highly changeable flowing parts of centrifugal compressors gas pumping machines. Dis ... Cand. tehn. Sciences. Kazan, 2005 (in Russian)]

[3] Галеркин Ю.Б. Вопросы проектирования проточной части центробежных компрессоров природного газа. «Компрессорная техника и пневматика в 21 веке». T. 2. Труды Международной научно-технической конферениии по компрессоростроению. Украина, Сумы: Изд-во СумГУ, 2004 [Galerkin Y.В. Design issues flowing part of centrifugal compressors of natural gas. "Compressor technics and pneumatics in the 21st century." V. 2. Proceedings of the International scientific and technical conference on the compressor engineering. Ukraine, Sumi: Publishing house of SSU, 2004 (in Russian)]

[4] Галеркин Ю.Б. Турбокомпрессоры. М.: Изд-во КХТ, 2010 [Galerkin Y.В. Turbochargers. M., Publishing house KHT, 2010 (in Russian)]

[5] Галеркин Ю.Б., Данилов К.А., Попова Е.Ю. Численное моделирование центробежных компрессорных ступеней (физические основы, современное состояние). Компрессорная техника и пневматика, 1993, 2 [Galerkin Y.B., Daniel K., Popova E.Y. Numerical simulation of centrifugal compressor stages (the physical basis, modern state). Compressor technics and pneumatics, 1993, 2 (in Russian)]

[6] Japikse D. Centrifugal Compressor Design and Performance. Concepts ETI. Inc, 1996.

[7] Демиденко Н.Д., Кулагин В.А., Шокин Ю.И. Моделирование и вычислительные технологии распределенных систем. Новосибирск: Наука, 2012 [Demidenko N.D., Kulagin V.A., Shokin Y.I. Modeling and computational technology of distributed systems. Novosibirsk, Nauka, 2012 (in Russian)] 
[8] Галеркин Ю.Б., Рекстин А.Ф., Солдатова К.В., Дроздов А.А. Верификация новых версий Метода универсального моделирования центробежных компрессоров по результатам экспериментов. Компрессорная техника и пневматика, 2015, 4 [Galerkin Y.B., Rekstin A.F., Soldatova K.V., Drozdov A.A. Verification of the new versions of the Unified Modeling Method of centrifugal compressors, according to the results of experiments. Compressor technics and pneumatics, 2015, 4 (in Russian)]

[9] Галеркин Ю.Б., Солдатова К.В., Дроздов А.А. Совершенствование методов расчета газодинамических характеристик промышленных центробежных компрессоров. Компрессорная техника и пневматика, 2013, 8 [Galerkin Y.B., Soldatova K.V., Drozdov A.A. Perfection of methods of calculation of gas-dynamic characteristics of industrial of centrifugal compressors. Compressor technics and pneumatics, 2013, 8 (in Russian)]

[10] Никифоров А.Г., Попова Д.Ю., Солдатова К.В., Соловьева О.А. Опыт обобщения результатов расчетного исследования безлопаточных диффузоров центробежных компрессорных ступеней с помощью нейронносетевой модели. Компрессорная техника и пневматика, 2015, 4 [Nikiforov A.G., Popova D.J., Soldatova K.V. Solovieva O.A. Experience generalization of results calculated studies bezlopatochnyh of diffusers of centrifugal compressor stages with the help of NEURONET model. Compressor technics and pneumatics, 2015, 4 (in Russian)]

[11] Никифоров А.Г., Попова Д.Ю., Солдатова К.В., Соловьева О.А. Использование нейросетевого моделирования для расчета энергетических характеристик центробежного компрессора. Компрессорная техника и пневматика, 2015, 3 [Nikiforov A.G., Popov D.J., Soldatova K.V., Solovieva O.A. The use of neuronet modeling for calculating the energy characteristics of a centrifugal compressor. Compressor technics and pneumatics, 2015, 3 (in Russian)]

[12] Никифоров А.Г., Попова Д.Ю., Солдатова К.В. Нейросетевые модели политропного КПД и коэффициента напора промежуточной ступени центробежного компрессора. Компрессорная техника и пневматика, 2015, 6 [Nikiforov A.G., Popova D.J., Soldatova K.V. Neuronet models of a polytropic efficiency and the coefficient of the intermediate stage centrifugal compressor head. Compressor technics and pneumatics, 2015, 6 (in Russian)].

[13] Труды научной школь компрессоростроения СПбГПУ. М.: Изд-во СПбГПУ, 2010 [Proceedings of the scientific school of compressor STU. M.: Publishing STU, 2010 (in Russian)]

[14] Селезнев К.П., Галеркин Ю.Б. Центробежные компрессоры. Л.: Машиностроение, 1982 [Seleznev K.P., Galerkin Y.B. Centrifugal compressors. L.: Mechanical engineering, 1982. (in Russian)]

[15] Галеркин Ю.Б., Рекстин А.Ф., Солдатова К.В., Дроздов А.А. Альтернативный способ расчета характеристики коэффициента теоретического напора центробежного компрессорного колеса. Компрессорная техника и пневматика, 2016, 6 [Galerkin Y.B., Rekstin A.F., Soldatova K.V., Drozdov A.A. An alternative way to calculate the characteristics of the theoretical pressure ratio of the centrifugal compressor wheel. Compressor technics and pneumatics, 2016, 6 (in Russian)]

[16] Галеркин Ю.Б., Солдатова К.В. Принципы моделирования напорной характеристики центробежного рабочего колеса. Компрессорная техника и пневматика, 2016, 1 [Galerkin Y.B., Soldatova K.V. Principles of modeling the pressure characteristics of centrifugal impeller. Compressor technics and pneumatics, 2016, 1 (in Russian)].

$$
-397-
$$


[17] Кулагин В.А., Рекстин А.Ф. Эффективное газодинамическое проектирование при создании и модернизации центробежных компрессорных установок. Компрессорная техника и пневматика, 2014, 5 [Kulagin V.A., Rekstin A.F. Efficient gas-dynamic designing of at creation and modernization of centrifugal compressor installations. Compressor technics and pneumatics, 2014, 5 (in Russian)] 